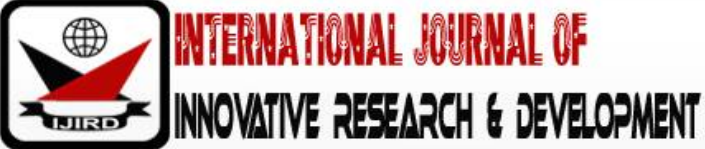

ISSN 2278 - 0211 (Online)

\section{Vulnerability and Responses of Farm Households to Socio-economic Shocks: Evidence from Tarkwa-Nsueam Municipality of Ghana}

\author{
Charles Boateng Opoku \\ Development Researcher, Department of Center of Distance Education (CoDE), \\ University of Cape Coast, Ghana
}

\begin{abstract}
:
Farmer households in Sub-Saharan Africa face severity of exposure to socio-economic shocks, which partly explain the gap in the level of development among countries in this region. These socio-economic shocks are the events that are capable of reducing group or individual's well-being, such as illness, unemployment, or drought, which may cause or compound poverty. Studies on sustainable livelihoods in Ghana and the world at large are mostly characterized by factors that influence poverty and food insecurity. Though there have been many studies on the impacts of socioeconomic shocks on rural livelihoods in Ghana, the study adds to the many voices calling for re-look at the policy formulation and management of rural farmer livelihoods in Ghana. Using a total sample of 385 farmers selected from five communities in the Tarkwa-Nsueam municipality through a stratified sampling procedure and both qualitative and quantitative analysis, the findings show that mining activities, poor road conditions, limited access to market information, poor environmental condition, limited access to land, and credit render farmers in the municipality vulnerable. The analysis revealed that the farmers employ individual responses to reduce vulnerability and enhance livelihoods, including artisanal mining (galamsey) activities, trading, borrowing from well to do community members and other menial jobs. Also, the farmers benefit from external intervention from the municipal agriculture development unit, such as education on social issues and training on farming techniques. The study also discovered the absence of agriculture assisted Non-Governmental Organizations in the study community. The study highlights the need for strong policies and more development partners and stakeholder engagements to reduce farmer vulnerability.
\end{abstract}

Keywords: Farm households, vulnerability, responses, socio-economic shocks, Tarkwa-Nsuaem Municipality, Ghana

\section{Introduction}

The economies of West African countries are driven by agriculture, which forms the basis of growth and primary source of livelihood for three out of four of the world's poor, as indicated by the Intergovernmental Panel on Climate Change (IPCC, 2007). These economies in West Africa are increasingly at risk of instability in global product prices and economic recessions, and Ghana is not an exception. The agriculture sector contribution to the Gross Domestic Income of Ghana has since seen constant declined in recent times. Until the year 2007, agriculture contribution to GDP in Ghana, for instance, was above 35 percent and has declined steadily in recent times to 19 percent (Ghana Statistical Service, 2012). Despite the decline in the aggregate agriculture contribution to GDP, crop production remains the most significant contributor to the agriculture sector, with 66.2 percent (Ministry of Food and Agriculture, 2011). Several reasons account for the recent decline in the aggregate agricultural production in Ghana, which may include farmer vulnerability to socioeconomic shocks.

Shocks can be illness, unemployment, drought, price volatility, and natural disaster, which are capable of reducing group or individual well-being and may themselves cause or compound poverty. These shocks come in the form of covariate shocks such as armed conflict, changes in food prices, drought, flood and social unrest which affect communities or countries, and idiosyncratic shocks such as illness, injury, crop failure and death which affect only individuals or households (World Bank, 2008). Idiosyncratic shocks are peculiar to individuals or families and geographical elements are often least considered in the cause of shocks but the ability to cope with these shocks individually is most often emphasized; this is what the study highlighted. Shocks are often classified into natural shocks (e.g., flood, drought, and earthquake), Economic shocks (e.g., price volatility, loss of remittances and job loss), social shocks (e.g., crime, eviction, and land conflicts) and health shocks (e.g., illness, injury, and death). Socio-economic shocks affect every aspect of household livelihood in different ways such that while economic shocks bring about price volatility and loss of a job, social shocks bring about theft and conflict, and health shocks lead to illness and death which have considerable effects on individual households. These shocks are often sudden and affect mostly the vulnerable in society and the ability to cope with such shocks is always a challenge. Shocks such as volatility in market prices of both inputs and outputs and inadequate road infrastructure facilities are more prone in the rural communities in Africa (Collier and Gunning, 1999). 
The remoteness farm communities and threatened livelihoods of households render them more vulnerable to specific shocks that are not well protected.

Therefore, the purpose of this paper is to examine the vulnerability and responses of farmer households in Tarkwa-Nsuaem municipality, one of the farming dominated municipalities in the western region of Ghana. Thus, the study's aims are twofold. First, to explore the nature of socio-economic shocks and their effects on farmer households and second to identify the responses of affected farmer households and other stakeholders. In doing so, the study seeks to answer the following research questions;(1) What are the effects of socio-economic shocks on farmer households? And (2) What responses are adopted by farmer households and other stakeholders to reduce vulnerability?

\section{Literature Review}

\subsection{Vulnerability Context and Livelihood Options}

Vulnerability studies have gained prominence in literature for reasons to enhance livelihoods and alleviate poverty, especially among developing countries and rural poor. Many scholars have defined vulnerability in varied forms to reflect the scope and conceptualization in their work. According to Moser (1998), vulnerability is the capacity of individuals to withstand the threat posed by the unfavourable social, economic, and health conditions. This paper adopts the Intergovernmental Panel on Climate Change definition of vulnerability as the degree to which an environmental or social system is susceptible to and unable to cope with the adverse effects, including price volatility and conflicts (IPCC, 2007). This allows for a broader conceptualization of the extent to which farm households are unable to cope with the harmful effects of socio-economic shocks on livelihoods and also allows for the identification of the various responses of farmer households. The vulnerability context describes the space that the farmer households live, which includes critical trends, such as technological trends or population trends. It also contains shocks such as inflation and seasonality, which defines the way prices, employment opportunities and production vary with seasons. The degree or rate of vulnerability varies across space and what makes one region or community vulnerable may be different from another (Brooks et al., 2005; Füssel, 2010). For instance, Simelton et al. (2012) argued that certain factors are significant in determining adaptive capacity by highlighting that socio-economic factors that drive cereal production's vulnerability to drought depend on the type of cereal as well as the region of the world.

The Department for International Development (1999) defines livelihood to include the capabilities, assets (including both material and social resources) and activities required for sustainable living. Therefore agricultural livelihoods are those potentials (including competencies and skills), assets (e.g., land, shelter, and social resources), and measures that are needed to enhance or sustain the livelihood of a farm household. An agricultural livelihood is sustainable when it can cope with and recover from shocks, maintain or enhance its capabilities and assets, and providing sustainable livelihood opportunities for the future generation. However, a livelihood is considered vulnerable when the sustenance is unable to cope with and recover from shocks, maintain or enhance its capabilities to offer protection to farm households in the face of shocks. These sustainable livelihood assets, according to Mcleod (2001), comprise natural or environmental capital, human capital, financial or economic capital, social capital, and physical capital.

Farm households are exposed to shocks at various degrees and levels from one community to another with other economic, demographic, and environmental characteristics. Though some urbanites may be as weak as rural households, infrastructure and other public goods provide them with insurance against exogenous shocks of all kinds, including adverse weather and other national disasters, disease, as well as certain types of political and economic exploitation which sometimes reduce their level of vulnerability. For example, urban farm households are less likely to be affected by deplorable roads, access to quality healthcare, and crop seedlings, yet this is a significant risk for farmers everywhere. Across the tropics, farm households are already exposed to diverse forms of shocks in their farm productive activities such as pest and disease outbreaks, high temperature and low or very high rains, and market distortions, which often affect the household livelihood. According to Harvey et al., (2014), since farm households depend on agriculture to enhance their livelihood, any reduction in the productivity of farm households may significantly affect the well-being of the homes due to limited coping strategies. Recent studies also show that high temperatures have negative implications on crops such as rice, maize which are commonly cultivated by small scale farmers. The variability in temperature coupled with other social and economic shocks render farm households more vulnerable as emphasized by Harvey et al. (2014), pest and disease outbreaks also increase during periods of poor weather and often lead to reduced yields and drought.

There is also an increasing load of urban farm households of paying high utility bills, transportation charges, and limited access to farmlands as compared to access to farmlands in rural areas. Feeny et al. (2013) argued that rural and urban farm households equally suffer the burden of price shocks, such as rising food prices, which comes as a result of rising fuel prices and transportation costs. In rural areas where farmers depend on trucks and boats as a significant source of transporting their farm produce, it is challenging to carry all their goods to markets and, on time, access alternative livelihood and new technology in farming, which are often classified as vulnerable factors.

The limited access to land by farm households in the urban areas has a significant impact on their productivity. The growth in the population levels and the increasing rates of urbanization increases pressure on farmlands in urban areas and reduce the supply of farmland for cultivation. This is a result of the continued migration of rural folks to the urban centers considering the available farmlands that exist in rural communities. Farmlands in urban areas are also characterized by disputes which often hinder agricultural production. The continuous trend of this nature raises issues of food supply and food security. This eventually leads to the increasing dependence of urban farmer households with low productivity levels on particular imported food such as rice and tinned fish to keep their family going. It can also be seen 
that though farm households in rural areas get some amount of foods from local stores, they maintain productive farms that relieve them in times of increasing prices of such foods or low household income.

In contrast, rural households are constrained by limited livelihood alternatives and little application of technology in their farm activities (Maebuta and Maebuta, 2009), which makes it difficult for rural households to cope vigorously with shocks. The remoteness of farm communities, especially in the face of poor road infrastructure, also increases the vulnerability of farmers. Agricultural communities in Ghana are characterized by a weak and uneven distribution of road infrastructure that connects farms to cities (MoFA, 2011). During raining seasons, most of these roads that connect farms to the market become very poor and are difficult to access. Farmers also pay higher prices for farm inputs, particularly from local markets in remote areas, which reduce their profit margins.

\subsection{Vulnerability as a Result of a Social Phenomenon}

Persistent exposure to shocks is a crucially important source of vulnerability. The study defines social shocks as continuous exposure to social stresses without enough fallback options to relieve one of such harm. Those characteristics that often influence social vulnerability include age, gender, ethnicity, and socio-economic status. Other features that change vulnerability such as the physically or mentally challenged and the homeless are often among those that lack the standard social safety nets necessary in recovering from a disaster. Other social factors that render household vulnerability include member illness, death, theft, eviction from land, money cheating, land litigation, and abandonment of women (Damas and Rayham, 2004). Factors such as high household sizes, poverty and hunger, poor health, low levels of education, gender inequality, fragile and hazardous location, and lack of access to resources and services, including knowledge and technological means operate to weaken the capacity for self-protection, obstruct or diminish access to social protection, delays or complicate recovery, or expose some households to more significant or more frequent hazards than others. Aysan (1993) argues that lack of access to information and knowledge, lack of public awareness, limited access to political power and representation make households socially disadvantaged and their vulnerability exacerbates further.

\subsection{Vulnerability as an Outcome of Socio-Economic Engagements}

The persistent exposure to risks factors by farm households endanger the livelihood assets of households and limits the adaptation strategies of farmer households to enhance their livelihood since farmers often hastily reallocate their resources by selling their initial livelihood capital assets, for example selling off farmland in the face of drought to pay for medical care or start trade (Bryceson, 2002). Changes in price bring about double problems for some farmer households, which include high pre-harvest food prices for consumers and low post-harvest commodity prices for farmers. Farmer households, especially those on a subsistence basis, are induced by urgent cash needs to sell off their produce immediately after the harvest in the face of lack of storage facility and poor market communications at secondary and tertiary levels to drive prices. Also, the majority of farmer households' livelihoods depend on cultivation, which often meets the most challenging time of the year, usually the wet season, especially before the first harvest. In most of these cases, food supply falls, food prices are high, work is hard, and infections are prevalent. Malnutrition, morbidity, and mortality all increase, while body weights decline. The poorer households, women, and children are particularly vulnerable. Birth weights drop and infant mortality rises. Child care is inadequate. Desperate people get indebted as a result of borrowing to ease the household burden during both the hungry season and the sick season. It is also the season of poverty ratchet effects, that is, of constant downward movements into poverty through the sale or mortgaging of assets, the time when poor farm households are most likely to become vulnerable.

\subsection{Vulnerability as an Inability to Respond Appropriately to Socio-Economic Shocks}

The study of vulnerability and responses are inseparably linked together. These responses are sometimes suggested as positive alternatives to the inherently negative meaning of vulnerability, which tends to focus on people's weaknesses instead of recognizing the many ways in which they can cope with hazards. The concept of coping mechanisms or responses borrowed from the literature on socio-economic stability has been used in many vulnerability studies to denote the ability of a household to respond to and quickly recover from harmful events. The views expressed in the literature range from those who consider vulnerability to be the flip side of responses to those who regard response as one of the components of vulnerability (contributing to vulnerability reduction). A pragmatic approach combines both notions and acknowledges that all people are vulnerable to some things, and have some capacity for response at the same time. Most vulnerable are the children and elderly female (or widowed) members belonging to a minority ethnic group or religion of the poor class and immigrants. These are the people or the group of people who do not have access to some crucial assets, have little political voice to engender any change. These groups of people have the most potent strength to survive the worst human (or inhuman) conditions. They are surviving in such circumstances and yet are considered vulnerable. They become weak because they lack resources, and they have reduced mobility. Ethnic groups are vulnerable not because they do not have strength for survival or rebuilding, but because they have reduced access to other factors such as land, services, and information (Chiwaka \& Yates, 2004).

Further, these are the group that usually does not have access to the resources distributed during dealing with socio-economic shocks. Women generally have less access to resources and typically have less representation in decision making at all levels (Wisner, 2003). One of the groups that suffer more in the events of socks is women. Economic dependence on men makes them highly vulnerable in developing countries. They are the victims of disasters as well as the victims of the male-dominated social order that may escalate following an accident. Ela R. Bhatt, (1998), argues that Women are vulnerability-locked mostly because of the existence of particular social dynamics such as the lack of 
ownership or inheritance of productive assets, education and access to institutional support which can enhance their livelihood and empower them to withstand or absorb shocks from market forces. Vulnerability compels women to expand their efforts to earn a wage, especially female-headed farmer households, to address specific household needs and chores such as injured children and, at the same time engaging other livelihood options to increase household income. Widespread subordination of women has meant that women typically must bear more stress than men, including a preoccupation with dependent children. Due to the general absence of employment opportunities and the high incidence of woman-headed households particularly among farmer households who are not native, increasing numbers of women and girls are forced into socially unacceptable forms of wage labour that often make them more vulnerable. In some communities, many displaced women may end up as prostitutes, hoping to gain income to sustain their families. The longer the situation of unemployment remains unresolved, the higher the likely incidence of vulnerability. Social constraints on movement, low wages, lack of job for widows and deserted women are the most vulnerable.

\subsection{Responses of Farmers to Socio-Economic Shocks}

In the events of exposure to shocks, farmers employ various coping mechanisms to sustain or recover from such situations. The level of access to capital by farmers directly influences the type of response that farmers apply during difficult times to improve their livelihood and mitigate the outcome of shocks (Borner et al., 2012). The most common coping mechanism used by farm households is to cut down consumption levels during hard times or turn to consume more goods that are most available such as cassava and other tubers. Some farm households mainly resort to consuming wild yams during a lean season where their harvest often meets the shortage of some crops such as maize and crops. Other farmers also engage in other activities such as offering their factor services to fellow farmers purposely to obtain a substantial amount of income. This may be seen as an off-farm activity since they are not working as producers utilizing their own factors services. In spite of the several fall back mechanisms that are relied upon by farmers to reduce the outcome of shocks, many farmers often go through the problem of persistent food insecurity indicates that the mitigating measures employed by farmers are inadequate. There are limits to how a farmer applies specific standards during difficult times. For instance, the other employment opportunities that exist for farm households may coincide with weeding and planting timelines, which may not allow enough time for farmers to mitigate the full impacts of shocks.

According to Anne-Claire (2009), robust institutional arrangements and effective coping mechanisms adequately help to reduce farm households' vulnerability during times of stress. These strategies or options may include amending agricultural policies to target increasing welfare of farmers and increase productivity, policies that ensure economic development, plans to reduce poverty, market restructuring and strengthening institutional arrangements and governance structures to improve farmer productivity and livelihood directly. Many policy options and strategies that have shown some level of success by increasing agricultural productivity in some part of Africa include supply of improved seed varieties to farmers, supply of fertilizer and training on good farming practices, development of irrigation systems, provision of technical inputs, enhancing state of road infrastructure and access to markets, providing more exceptional technical support and extension services to farmers, and providing access to timely climate information. Harvey et al. (2014) emphasized that policymakers can turn their attention to specific areas that can help to ensure a sustained increase in agricultural productivity and enhance the livelihoods of farmers in the short term. One of these areas that call for urgent attention is the need to expand and strengthen farmer extension services that will provide technical advice and effective farm management practices to include both ex-ante and ex-post of farm activities, to train farmers on the adoption of modern farm management practices and to encourage learning among themselves. Effective extension service to farmers has shown to be effective in farmers' adaptation to current farm practices in responding to weather volatility.

It is also imperative that development planners and policymakers protect the natural ecological systems that farm households most often use as safety nets. These efforts by policymakers are crucial and require stringent measures since farm households often turn to the forests as a source of raw materials used to repair or reconstruct their affected homes that are destroyed by sudden events. For this reason, to maintain and also develop the wellbeing of farm households, policymakers must be able to make efforts to conserve and sustain the natural ecological system.

\section{Theoretical Framework}

A theoretical framework of the study is situated in the sustainable livelihood framework (DFID, 1999). It assumes that all other things being equal, active participation of public and private institutions through policy formulation and implementation, and other interventions will lead to specific livelihood outcomes such as increased earnings, improved health status, increased access to education, and more sustainable use of natural resource base. The theory identifies the various livelihood assets, links them to causes of household vulnerability and fall back strategies or interventions that are used as mitigating factors. The framework establishes the existence of climate change, the impact of economic, environmental and social shocks in vulnerability studies as well as seasonality, trends over time and space.

The sustainable livelihood approach places emphasis on the efforts to eradicate poverty and building capacities of the poor to ensure economic growth and sustenance. The framework identifies five types of capitals that are essential to building livelihoods of households. These capitals are natural capital (e.g., soil, water, air, environmental services.), Human capital (e.g., skills, knowledge, labour, good health and physical capability), Economic or financial capital (e.g., credit/debt, savings and other economic assets), Physical capital (e.g., roads, buildings, production equipment and technologies) and Social capital (e.g., networks, social claims, social relations, affiliations and associations). All of these capitals are important to the livelihood of households although the level or the measure of their significance may differ from household to another over time. There are many efforts to directly link the livelihood capitals to determine the incidence of poverty with the assumption that shows an inverse relationship between capital and poverty. That is, less capital implies greater 
vulnerability and shows greater poverty. These capitals are exposed to shocks over time, which turns to render households vulnerable.

Climate change often has a significant impact on the natural and physical capitals of households. This comes in the form of too many rains or too little rains needed for farming. Too much rain brings about floods that cause erosion and subject the physical structures into the grievous state, while minimal storms also affect crops that need water to do well during the planting season. This mainly affects the poor farmers who depend heavily on rains and have no irrigation system. In any case, farm households record low yields and lose valuable assets that directly affect their livelihood. The severity of drought, in the long run, may impact profoundly on households' capital assets such as human and social capitals as many people in rural communities migrate in search of opportunities in the urban areas. Sustainable Livelihood Approach provides a basis to understand how the increasing trend of climate change impacts households' livelihoods as a factor that renders household vulnerable and the strategies that are employed to militate against their vulnerability (Elasha et al., 2005).The perception of vulnerability considers how households are exposed to dangers, as they are easily harmed and the protection that they lack (Brauch, 2002). Vulnerability is not merely a function of exposure but also the ability of households to adapt to change; therefore, if the strength of the people to adapt to changes remains unchanged, the increased exposure will lead to greater vulnerability.

\section{Research Design and Methodology}

A cross-sectional design was used for this study since the vulnerability and responses of farmer households are not amenable to experiment. The focus of the study involved pool farmer household heads with diverse demographic characteristics such as age, marital, and occupational status. Both quantitative and qualitative design was also considered for the study. The data collection of the study was done primarily using an interview schedule and structured questionnaire administered to obtain data from the sampled farm household heads and Municipal Agriculture Development Unit, respectively. Within each farmer household, a resident household head was selected and interviewed by the researcher and five trained graduates who worked as enumerators. The interview schedule was administered in August 2017, spanning fourteen days while the questionnaire was given to the Municipal Agriculture Development Officer in Municipal Agriculture Development Unit to respond after introducing the purpose of the study by the researcher. Where necessary, calls were made to clarify any conflict before the agriculture development officer responded. The questionnaire administration also started in August 2017 and lasted for three days.

Since agriculture in the municipality is primarily rural activity, a stratified sampling technique was used to divide the study area into five strata, and five rural communities were randomly selected to include Kyekyewere, Kadadwen, Dompim, Esuoso and Anyinase as shown in Figure 1. The target population comprised both farm household heads and Municipal Agriculture Development Unit. Using data from the 2010 population and housing census, the total number of agriculture households in the Tarkwa-Nsuaem municipality was 8,469 .

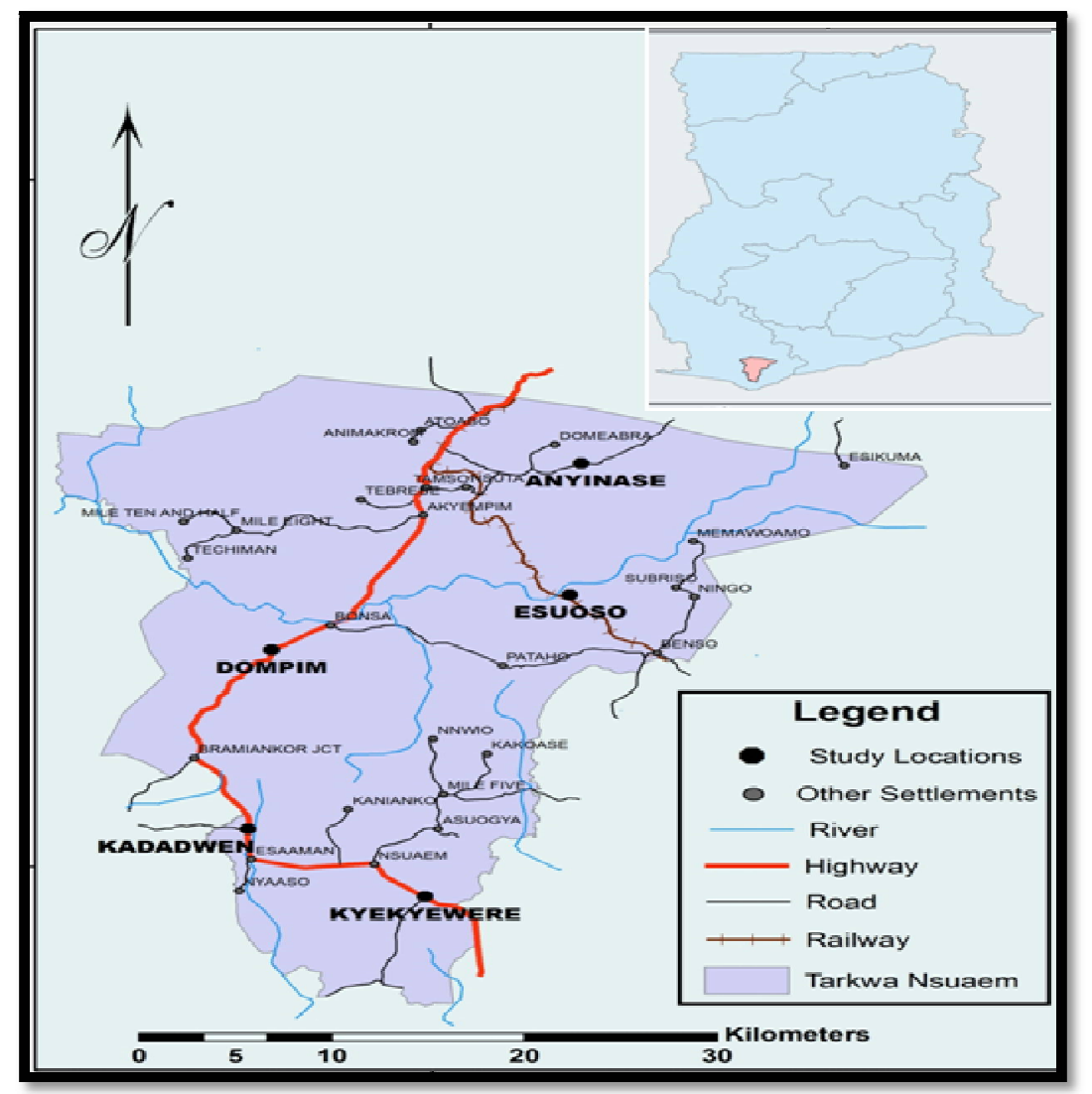

Figure 1: Location of Tarkwa-Nsuaem Municipality and study communities Source: Adapted from Tarkwa-Nsuaem Municipal Assembly, 2016 
Using a confidence level of $95 \%$ and margin of error of 5\%, a sample size of 385 farm household heads were randomly sampled to respond to interview schedule using Krejcie and Morgan (1970) sample size determination for research activities. The interview protocol included questions that sought to solicit the factors that could influence the vulnerability and responses of farmer households. The findings from the literature partly informed these questions. Besides, new items were added to reflect location characteristics. Broad categories of data, such as demographic characteristics as well as access to land by farmers, have been discussed. Key focuses of the study, such as types of socio-economic shocks, farmer vulnerability, and the effects of these shocks as well as the responses of farmers in Tarkwa-Nsuaem municipality, have been discussed.

\section{Results}

The sampled population was dominated by male-headed farmer households (73.77\%), and the majority of the respondents fell in the 41-50 age brackets (42.60\%). Approximately $78.35 \%$ of the respondents had attained some level of formal education, with $29.61 \%$ having achieved senior high school education while $65.97 \%$ of the sampled farmers were married. Majority of the sampled farmer household heads were natives of the Municipality, accounting for about $72.21 \%$ of the responses (see Table 1). The residential status of farmer households directly affect access to land by farmers as $74 \%$ of the sampled farmers accessed land through inheritance; $21 \%$ of the farmers obtained farmland through sharecropping, and five percent accessed land through renting.

\begin{tabular}{|c|c|c|}
\hline Variable & Frequency & $\%$ \\
\hline \multicolumn{3}{|l|}{ Gender } \\
\hline Male & 284 & 73.77 \\
\hline Female & 101 & 26.23 \\
\hline Total & 385 & 100.00 \\
\hline \multicolumn{3}{|l|}{ Age of household head } \\
\hline below 31 & 6 & 1.56 \\
\hline $31-40$ & 81 & 21.04 \\
\hline $41-50$ & 164 & 42.60 \\
\hline $51-60$ & 89 & 23.12 \\
\hline $60+$ & 45 & 11.69 \\
\hline Total & 385 & 100.00 \\
\hline \multicolumn{3}{|l|}{ Educational level of household head } \\
\hline Non-formal education & 83 & 21.56 \\
\hline Primary & 76 & 19.74 \\
\hline JHS & 98 & 25.46 \\
\hline Secondary & 114 & 29.61 \\
\hline Tertiary & 14 & 3.64 \\
\hline Total & 385 & 100.00 \\
\hline \multicolumn{3}{|l|}{ Marital status of farm household } \\
\hline Married & 39 & 10.13 \\
\hline Separated & 23 & 5.94 \\
\hline Divorced & 69 & 17.92 \\
\hline Single & 385 & 100.00 \\
\hline \multicolumn{3}{|l|}{ Total } \\
\hline Residential status & 278 & 72.21 \\
\hline Native & 107 & 27.79 \\
\hline Migrants & 385 & 100.00 \\
\hline Total & & \\
\hline
\end{tabular}

Table 1: Relevant Characteristics from Sampled Farmer Household Heads Source: Field Survey, 2017

\subsection{Types of Socio-economic Shocks}

The respondents revealed the shocks that affect and trigger a decline in their livelihoods or well-being (see Table 2). These shocks were categorized into social and economic shocks, and the number of times farmers cited these shocks was used to rank the shocks. The activities of mining firms in the study communities were most mentioned among sampled farmers (65\%) followed by the sickness of household members (42\%), poor road conditions (41\%), while 38\% of farmers revealed low prices for agriculture output. 


\begin{tabular}{|c|c|c|c|c|}
\hline \multirow{2}{*}{ Types } & Vulnerable factors identified & $\begin{array}{c}\text { Number of times cited } \\
\text { by farmers }(\boldsymbol{n}=\mathbf{3 8 5})\end{array}$ & $\begin{array}{c}\text { Percentage of } \\
\text { respondents }\end{array}$ & $\begin{array}{c}\text { Ranking of } \\
\text { cases }\end{array}$ \\
\hline \multirow{3}{*}{ Social } & Mining activities & 249 & 65 & $1^{\text {st }}$ \\
\cline { 2 - 5 } & Poor road condition & 158 & 41 & $3^{\text {rd }}$ \\
\cline { 2 - 5 } & Sickness of household member & 161 & 42 & $2^{\text {nd }}$ \\
\cline { 2 - 5 } & Lcand conflict & 27 & 22 & $7^{\text {th }}$ \\
\hline \multirow{3}{*}{ Economic } & Pest and diseases & 83 & 36 & $6^{\text {th }}$ \\
\cline { 2 - 5 } & High cost of inputs & 138 & $5^{\text {th }}$ \\
\cline { 2 - 5 } & Low prices of output & 147 & 38 & $4^{\text {th }}$ \\
\hline
\end{tabular}

Table 2: Types of Shocks Revealed by Farmers

Source: Author's Field Data, 2017

In responding to shocks, the study solicited information on the adaptation strategies that the farmer households employ to cushion themselves to ensure their livelihoods were not worsened. In difficult times, about 44 percent of the farmers interviewed engaged in menial jobs, 26 percent involved in trade, 13 percent said that wives assisted in food acquisition, 10 percent sought assistance from friends and relations, and seven percent found a loan from well to do community members (Table 3). The study discovered that responses among farmer households were gender sensitive such that majority (38\%) of Male headed farmer households engaged in menial jobs, while the majority (17\%) of femaleheaded farmer households involved in trading.

\begin{tabular}{|c|c|c|c|c|c|c|}
\hline \multirow{2}{*}{ Mitigation measures } & \multicolumn{3}{|c|}{ Sex } & \multicolumn{3}{c|}{ Total } \\
\cline { 2 - 7 } & \multicolumn{2}{|c|}{ Male } & \multicolumn{2}{c|}{ Female } & \multicolumn{2}{c|}{} \\
\cline { 2 - 7 } & Frequency & Percent & Frequency & Percent & Frequency & Percent \\
\hline Engage in other menial jobs & 147 & 38.2 & 22 & 5.7 & 169 & 43.9 \\
\hline Trade & 33 & 8.6 & 67 & 17.4 & 100 & 26.0 \\
\hline Wife assists in food acquisition & 50 & 13.0 & 0 & 0.0 & 50 & 13.0 \\
\hline $\begin{array}{c}\text { Seeking assistance from } \\
\text { friends and relations }\end{array}$ & 33 & 8.6 & 6 & 1.6 & 39 & 10.1 \\
\hline $\begin{array}{c}\text { Taking loans from well to do } \\
\text { community members }\end{array}$ & 21 & 5.5 & 6 & 1.6 & 27 & 7.0 \\
\hline Total & 284 & 73.8 & 101 & 26.2 & 385 & 100.0 \\
\hline
\end{tabular}

Table 3: Responses by Sampled Farmers

Source: Author's Field Data, 2017

\section{Discussion and Implications}

\subsection{Farmer Vulnerability}

The majority of the farmers interviewed revealed that activities of large scale mining, small scale mining, and illegal mining (galamsey) activities turn their farmlands into minefields. The farmers indicated that there was no resettlement arrangement for their farms, though compensations were most cases given to them whenever their farmlands were taken or affected through the activities of mining companies. This keeps farmers out of farming until they secure another land for their operations while illegal mining activities destroy infant crops and degrade their farmland. Also, sicknesses among farmer households were identified as one of the events that impact their livelihood. Farm household heads were asked how often household members fall sick, and 39 percent of the farmers said quarterly, 31 percent scored yearly, 18 percent said monthly and 12 percent said weekly. The most frequent ailments revealed by farmers were malaria and anemia. This is very crucial to the livelihood of farmer households since human resources, as well as financial support, become affected whenever a family member is struck down by sickness. A study by Bryceson (2002) revealed that when illness struck farm households, farmers began to reallocate resources by selling farmlands to pay for medical bills or engaged in other trade in other to increase household income to cater for additional health expenses. Similarly, the farmers revealed that whenever there is a decline in the household livelihood, they turn to engage in other economic activities such as trading to be able to meet household expenditure.

Roads that link farm fields to market centers are also crucial to ensure smooth flow of farm produce to market, thereby reducing post-harvest losses. Collier and Gunning (1999), argued that rural communities in Africa are commonly characterized by poor road infrastructure, similarly, eliciting information on the condition of roads from sampled farmers, 41 percent of the farmers revealed that their roads were poor, 33 percent scored it as well, and 26 percent scored as very good. The majority of farmers that cited road conditions as poor show the degree of effect that poor road infrastructure has on farming in the study community. The farmers acknowledged that during heavy rains, the roads that link their farms to markets become terrible making it challenging to transport farm produce to the market. 
Similarly, the farmers revealed three economic risks that impact their well-being included pest and disease outbreak, high cost of inputs and low prices offered for the output produced. The study revealed two groups of farmers; thus, farmers as consumers of farm produce and farm inputs, and farmers as consumers of inputs and suppliers of farm produce. Consumers of farm produce were those farmers who consumed agricultural produce during off farming season and net suppliers were those who consume their products and still had enough to sell during the off-farm season. Farmers that were net producers were constrained by lower prices offered for their products coupled with the problem of storage. They presented a paradox of selling their farm produce at lower prices during bumper harvest and buying the food items at higher rates during the lean season. The farmers attributed this phenomenon to limited storage facilities which often made them sell off their produce within a specified period to prevent spoilage. The farmers also revealed high prices of inputs such as inorganic fertilizers and other services such as transport fares.

Farmers also cited the outbreak of pests and diseases as one of the shocks that threatened their livelihoods. The study revealed that the majority of farmers had limited knowledge about the incidence and spread of pests and disease, while some attributed it to the seasonal occurrence. Elsewhere in Africa, pest and disease outbreaks increase during periods of poor weather and result in low yields and drought (Harvey et al., 2014). Furthermore, identifying the factors that render farmers vulnerable to these socio-economic shocks, the farmers listed a host of factors that render them vulnerable and exposed them to socio-economic shocks. They said the limited information on the market made it difficult for them to sell their farm produce in bulk and at favourable prices to optimize revenue and the difficulty to acquire inputs at affordable prices to enable them mechanized their farms. The limited information on the market, coupled with limited storage facility, made farmers hurriedly sell their farm products at lower prices to avoid spoilage. The continuous increase in prices of inputs and low income would imply a reduced ability of farmers to apply specific inputs such as pesticides and inorganic fertilizers and may cause others to discontinue the application of such inputs. The study adds to the argument of Collier and Gunning (1999) that volatility in market prices of both inputs and outputs are a common feature in rural communities in Africa. The study, moreover, emphasizes the lack of market information as another common feature in rural communities that render farmers more vulnerable to volatility in prices and consequently impedes their quest to enhance household livelihood.

Responses from the farmers revealed that poor road conditions pose a risk to them, especially when harvesting coincides with heavy rains. Farmers indicated that heavy rains rendered roads deplorable and delayed harvest whenever harvest coincides with heavy rains. In the words of Zhang et al. (2007), a good road network linking farms to markets indicate that farmers can be able to access markets on time to reduce post-harvest losses and increase farm household earnings to enhance farm household livelihood. This implies that deplorable roads, as revealed by the study, would be a setback in improving livelihood and render farmers vulnerable to shocks. The majority of farmers in the study area are always in competition with mining companies for land. The farmers indicated that securing another land for their farm activities becomes difficult whenever their farms are taken over by mining activities, and this makes farmers settle for relatively smaller farmland size to carry out their activities to sustain a household livelihood. Unlike the assertion of Feeny et al. (2013) that the difficulty in accessing land for farming is a phenomenon that confronts farm households in urban areas, the study presented otherwise since farmers revealed the difficulty in accessing land was mainly due to mining. Though elsewhere, the limited access to farmland may be due to growing population in the urban centers that tightens the supply of farmlands and reduce sizes of farmlands, the study however, discovered that limited access to land by farmer households is not limited to only the urban areas but also in the rural communities since the survey was carried out in rural communities. The implication is that many factors can influence access to land by farmers such as population growth, the natural resources available (e.g., mineral deposits), the social environment and significant economic activities carried in the area in question. In this study, it was discovered that the causes of decreasing sizes of farmlands among farmers were mainly due to the prevalence of mining activities.

Poor environmental conditions and feeding of household members coupled with limited skills of household members made farmer households vulnerable and more susceptible to sicknesses. They said that whenever a member of the household fell sick, it delays farming timelines for farm these activities. A study by Harvey et al. (2014) revealed that guinea worm caused temporary lameness and confined the sufferer to bed for as much as five weeks and has a peak incidence, which coincided with the planting season. Similarly, the sampled farmers revealed the effect of diverting income into the treatment of illness, thereby reducing household income.

\subsection{Effects of Socio-Economic Shocks on Farmer Households}

The study revealed household needs that were greatly affected when they are exposed to shocks. This led the study to assess the severity of those shocks on farmer households' livelihoods. About 53 percent of the farmers said children's education was affected, 44 percent indicated household feeding, and three percent said shelter (Figure 2). Children assist in the farm activities whenever there is a shortfall in the household farm labour due to sickness and during a period of harvest and also engage in the selling of output to increase household income. Thus, since children are made to forgo classes and work as farm labours and traders, it also gives a case to worry about the state education of the children. This implies that, in the event of shocks, household income reduces and affects expenses on the education of children and that children sometimes are made to stay at home until household income is enhanced enough to spend on education. It is at this period that children are made to also engage in trade to support the household income. 


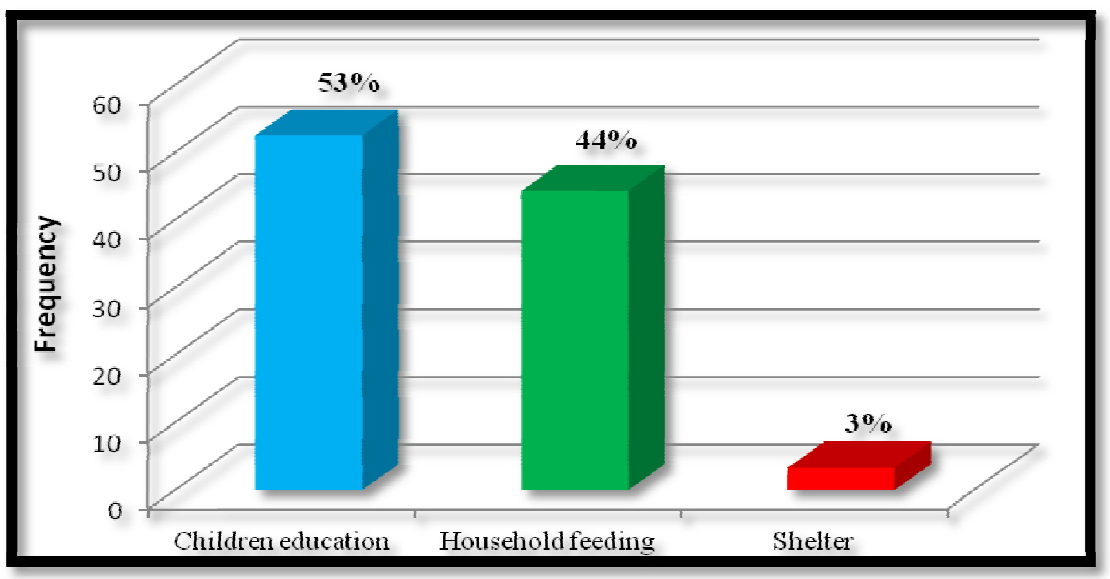

Figure 2: Household Needs That Were Much Hit Under Challenging Times Source: Author's Field Data, 2017.

Farmers also recorded cutting down the number and quantity of food intake due to limited household food supply during a lean season which often raises concern about the health implications of farmer households. Farmers revealed that in most cases, there were challenges in the payment of rents and refurbishment of their houses since income from farm produce was not enough to cater to such expenses. According to Adger (1996), vulnerability is not merely a function of exposure but also the ability of people to adapt to change; therefore, continuous exposure without a corresponding increase in adaptation often leads to greater vulnerability. This implies that constant exposure of these households' needs to shocks would make farmers more vulnerable, deteriorate their livelihoods, and leave them in abject poverty if appropriate responses are not adopted to reduce their vulnerability.

\subsection{Responses by Farmer Households}

According to Desiree (2011), these responses fill the void by addressing the soft perspective of vulnerability and allow rethinking about the prevalent risk. The significance of these strategies shift farmers from illness to health, from vulnerability to thriving, from deficit to protection and beyond ought not to be underestimated, as argued by 0'leary (1998). What was not recorded among the sampled farmers was the total reallocation of household resources to other non-farm activities or diversification processes, which represent a constructed change portfolio of activities and social support capabilities as the case in other parts of Africa revealed by Bryceson, 2002. In other countries where agricultural production plays only a limited role in the livelihood of farmers, migration of farmers from rural communities to urban areas in search of more sustainable occupation is a dominant feature in times of shock, as argued by Elasha et al. (2005). However, despite the difficulties the farmer faced in their farming, their responses showed their resilience in maintaining their farm asset but a section of them too revealed that persistent harm to their livelihoods without fall back strategies would propel them to abandon their productive activities in search for greener pastures in the urban areas.

In the course of sustaining farmer livelihood, the Municipal Agriculture Development Unit (MADU) provides effective and efficient extension services, transfer of technology, the supply of inputs such as quality seeds and fertilizers to farmers. This is to promote rural development, reduce the incidence of poverty among farm households and generally improve the annual agriculture average growth rate (NDPC, 2014). According to MADU, there were six extension officers in the municipality with the ratio of a farmer to an extension officer of 1000:1. Harvey et al. (2014) argued that one of the key potential areas for policymakers to focus on helping to increase agricultural productivity and improve the livelihood of farm households in the short term is the need to increase farmer access to extension services, enhance the provision of technical information and training on effective farm management practices. The limited access to extension services by farmers in the municipality implies that farmers fall short in ex-anti and ex-post farm activities which adversely affect their livelihoods. Interventions provided by MADU were done through farmer-based organizations, radio talk shows and provision of direct extension services. The formation of these farmer-based organizations was to facilitate the provision of extension services since there were limited extension service agents in the municipality. The establishment of FBOs helped to reach out to many farmers with extension services, where selected farmers were given the training to train others. The Municipal Agriculture Development Unit educates farmers on gender and social issues such as HIV and AIDS, EBOLA, AVIAN INFLUENZA which help to improve the health status of farmers. Another technical support provided to farmer households is improved crop variety, training in land preparation, planting techniques, fertilizer application, and harvesting of crops.

\section{Conclusions, Limitations and Future Research}

Generally, the study concludes that though external factors mostly cause farmer vulnerability, continuous exacerbating their vulnerability can also be the cause of the actions of the farmers themselves in the attempt to respond to exposure to shocks. Key among vulnerable factors identified by farmers were mining activities, limited access to extension services, poor environmental conditions, inadequate government support and poor feeding. The continuous occurrence of these factors without stringent mechanisms or responses, in the long run, will further worsen farmer livelihood and conditions thereby reducing productivity and income of farmer households and consequently making it difficult for farmers to address particular basic household needs such as feeding, children's education and shelter. Though the study 
revealed responses that farmers employed to reduce vulnerability and strengthen their capacity to deal with shocks, the reactions were said to be inadequate to relieve farmers of their vulnerability and in most cases, the responses themselves made the farmers worse off in the long run. Also, the external intervention by the Municipal Agriculture Development Unit to reduce farmer vulnerability does not directly address the vulnerable factors. To address vulnerability among farmer households and enhance the livelihoods, other development partners, as well as government, must focus on policies that aim at directly reducing farmer vulnerability. For instance, institutions and stakeholders should be strengthened and supported to enforce land-use laws and institute stringent punishment to offenders who are found guilty. This will help to reduce the menace of illegal mining activities and other activities that destroy agriculture land. Similarly, there must be a policy to regularize small and large scale mining companies such that farming communities will not just be resettled when the town is converted to mine filed, but also arable lands are secured for farmers whose farms are caught up by mining activities to enable farmers to remain in their farming activities and sustain production.

The study presented challenging choices of emphasis, mostly due to the encompassing nature of vulnerability studies or livelihood concepts. This means that almost any aspect of the way people go about their farming activities and living is potentially legitimate to investigate. This did not allow the study to examine the degree of effects shocks have on each livelihood option in the household due to inadequate resources and time constraints. Future research should, therefore, focus on investigating and analyzing the degree of effect of shocks on the livelihood options of households. Sampled household heads were sometimes absent and could not participate in the survey. In this case, the selection of different household heads was made. In such situations, the researcher relied on someone in the household who was conversant with how the activities of the household to respond to the questions. There were also cases of respondents exaggerating or concealing information for one reason or another. Perhaps some respondents associated the researcher with future developmental or employment activity. They felt it was their interest to portray themselves as worse than what they are. As much as possible, some careful cross-checking was done in such cases to reveal the real facts. Due to the high level of illiteracy among the farmers in the communities, a vast majority of farm household heads did not know their ages and these had to be estimated for them.

Based on the findings, it is suggested that governments and development partners intensify investment in road construction or reshaping poor roads in the rural or farming communities to enable farmers to transport their farm produce from farms to reduce post-harvest losses. Improving the health status of people in rural communities helps to reduced farmer vulnerability. The local agricultural development partners should enhance the supply of farm inputs by linking farmers to inputs suppliers to enable farmers to have easy access to improved and affordable seeds, chemicals, and fertilizers to boost production.

\section{References}

i. Adger, N. (1996). Approaches to vulnerability to climate change. Norwich: Center for Social and Economic Research on the Global Environment- CSERGE.

ii. Anne-Claire, T. (2009). The impact of agriculture shocks on household growth performance in rural Madagascar: Development Institutions \& Analyses de long Terme-DIAL.

iii. Aysan, Y. F. (1993). 'Keynote Paper: Vulnerability Assessment.' In: P Merriman and C. Browitt, eds., Natural Disasters: Protecting Vulnerability Communities, pp. 1 - 14.

iv. Bhatt Ela R. (1998). 'Women victim's view of Urban and Rural Vulnerability'. In John Twigg and Mihir R. Bhatt (Eds.) Understanding Vulnerability: South Asian Perspectives. Intermediate Technology Publication Ltd. London.

v. Brauch, Hans Gunther, 2002; Climate Change, Environmental Stress and Conflict. Background Paper for the Special Event 'Climate Change and Conflict Prevention', Bonn, 10 June 2002, 16 ${ }^{\text {th }}$ meeting of the Subsidiaries Bodies UNFCCC, Bonn (05 - 14 June 2002).

vi. Brooks, N., Adger, W.N. \& Kelly, P.M. (2005) The determinants of vulnerability and adaptive capacity at the national level and the implications for adaptation. Global Environmental Change,

vii. Bryceson, D.F. (2002). The scramble in Africa: Reorienting Rural Livelihoods. World Development, 30(5): 725-739.

viii. Borner, J.,Shively, G. Wunder, S. \& Wyman, M. (2012). How do rural households respond to economics shocks? insights from hierarchical analysis using global data.

ix. Chiwaka, E., \& Yates, R. (2004), Participatory Vulnerability Analysis: A Step-By-Step Guide for Field Staff: ActionAid International.

x. Collier, P. and Gunning, J.W. (1999). Why Has Africa Grown Slowly? Journal of economic perspectives, 13(3): 3-22.

xi. Damas, P. and Rayham, I. (2004). Vulnerability and Poverty: What are the causes and how are they related? Term paper for interdisciplinary course, international Doctoral studies, Center for Development and Research, University of Bonn.

xii. Desiree, C.D. (2011). A Formal Theory of Resilience, Master Thesis: University of Munster, Germany. pp 29-35

xiii. Department for International Development (DFID) (1999) Sustainable livelihoods guidance sheets. Accessed on June 15, 2016, from http://ww.eldis.org/go/livelihoods/.

xiv. Elasha, B. O. Elhassa, N. G., Ahmed, H. and Zakieldin, S. (2005) Sustainable livelihood approach for assessing community resilience to climate change: case studies from Sudan. Accessed on June 16, 2016, from: http://www.iflea.org/pdf/AIACC_WP_No017.pdf.

xv. Feeny, S., McDonald, L., Miller-Dawkins, M., Donahue, J. and Posso, A., (2013). Household vulnerability and Resilience to shocks: Findings from Solomon Islands and Vanuatu. Australian National University: Discussion Paper 2013/2.

xvi. FÜSSEL, H.M. (2010) Review and quantitative analysis of indices of climate change exposure, adaptive capacity, 
sensitivity and impacts. Washington, DC: The World Bank.

xvii. Ghana Statistical Service (GSS) (2012). 2010 Population and Housing Census. Summary report of final results. Accra: Ghana Statistical Service.

xviii. Ghana Statistical Service (GSS) (2014). 2010 Population and Housing Census. District Analytical Report. TarkwaNsuaem Municipality, Accra: Ghana Statistical Service

xix. Harvey. C. A., Rakotobe, Z. L. Nalini, S.R., Radhika, D., Razafimahatratra, H. Rabarijohn, R. H. Rajaofara, H. and MacKinnon. J. L. (2014). Extreme vulnerability of smallholder farmers to agricultural risks and climate change in Madagascar: UK- Royal Society:

xx. Intergovernmental Panel on Climate Change (IPCC) (2007). Climate change 2007: Impacts, adaptation and vulnerability. Contribution of working Group II to the Fourth Assessment Report of the Intergovernmental Panel on Climate Change. Cambridge: Cambridge University Press.

xxi. Krejcie, R. V., and Morgan, D. W. (1970). Determining sample size for research activities. Educational and Psychological Measurement, 30, 607-610.

xxii. Maebuta, Jack and Helen Esther Maebuta (2009). Household livelihoods in Solomon Islands squatter settlements and its implications for education and development in post-conflict context. Paper presented at the Australian Association for Research in Education International Education Research Conference. Canberra, Australia, 29 November - 3 December. Available from www.aare.edu.au/data/publications/2009/mae091005.pdf. Accessed November 20, 2016.

xxiii. Mcleod. R. (2001). The impact of regulations and procedures on the livelihoods and asset base of the urban poor: a financial perspective. Paper presented at the International Workshop on Regulatory Guidelines for Urban Upgrading, Bourton-on-Dunsmore

xxiv. Ministry of Food and Agriculture (MoFA) (2011). Agriculture in Ghana: facts and figures: Accra, Ghana.

xxv. Moser, C. O. N. (1998), The Asset Vulnerability Framework: Reassessing Urban Poverty Reduction Strategies World Development, 26, 1-19. http://dx.doi.org/10.1016/S0305-750X(97)10015-8

xxvi. National Development Planning Commission (NDPC) (2014). Ghana Shared Growth and Development Agenda (GSGDA) II 2014-2017, Accra: Ghana.

xxvii. O'Leary, C. J. (1998). Evaluating the effectiveness of Active labour Programs in Hungary: Upjohn Institute Technical Report No. 98-013. Kalamazoo, MI: W.E Upjohn Institute Technical for Employment Research.

xxviii. Simelton, E., Fraser, E.D.G., Termansen, M., Benton, T.G., Gosling, S.N., South, A., Arnell, N.W., Challinor, A., Dougill, A.J. \& Forster, P.M. (2012) The socioeconomics of food crop production and climate change vulnerability: a global scale quantitative analysis of how grain crops are sensitive to drought. Food Security

xxix. Wisner, Ben. (2003). At Risk: Natural Hazards, People's Vulnerability and Disasters-ER

xxx. World Bank (2008). Climate Change in Madagascar; Recent Past and Future. Washington, DC: World Bank.

xxxi. Zhang, X., Rockmore, M. and Chamberlin, J. (2007) A typology for vulnerability and agriculture in sub-Saharan Africa. Washington, DC: International Food Policy Research Institution 